\title{
New Races and Novel Strains of the Spinach Downy Mildew Pathogen Peronospora effusa
}

Chunda Feng, Katsunori Saito, Bo Liu, and Aurora Manley, University of Arkansas, Fayetteville, 72701; Katherine Kammeijer, Stacy J. Mauzey, and Steven Koike, University of California Cooperative Extension, Salinas, 93901; and James C. Correll, ${ }^{\dagger}$ University of Arkansas, Fayetteville, 72701

\begin{abstract}
Downy mildew disease, caused by Peronospora effusa $(=P$. farinosa $\mathrm{f}$. sp. spinaciae $[P f s])$, is the most economically important disease of spinach. Current high-density fresh-market spinach production provides conducive conditions for disease development, and downy mildew frequently forces growers to harvest early owing to disease development, to cull symptomatic leaves prior to harvest, or to abandon the field if the disease is too severe. The use of resistant cultivars to manage downy mildew, particularly on increasing acreages of organic spinach production, applies strong selection pressure on the pathogen, and many new races of $P f s$ have been identified in recent years in spinach production areas worldwide. To monitor the virulence diversity in the $P f s$ population, downy mildew samples were collected from spinach production areas and tested for race identification based on the disease reactions of a standard set of international spinach differentials. Two new races (designated races 15 and 16) and eight novel strains were identified between 2013 and 2017. The disease reaction of

$P f_{s} 15$ was similar to race 4, except race 4 could not overcome the resistance imparted by the RPF9 locus. Several resistance loci $(R P F 1,2,4$, and 6 ) were effective in preventing disease caused by $P f s 15$. The race $P f_{s} 16$ could overcome several resistance loci $(R P F 2,4,5,9$, and 10) but not others (RPF1, 3, 6, and 7). One novel strain (UA1014) could overcome the resistance of spinach resistant loci $R P F 1$ to $R P F 7$ but only infected the cotyledons and not the true leaves of certain cultivars. A new set of near-isogenic lines has been developed and evaluated for disease reactions to the new races and novel strains as differentials. None of the 360 U.S. Department of Agriculture spinach germplasm accessions tested were resistant to $P f s 16$ or UA1014. A survey of isolates over several years highlighted the dynamic nature of the virulence diversity of the $P f s$ population. Identification of virulence diversity and evaluation of the genetics of resistance to $P f s$ will continue to allow for a more effective disease management strategy through resistance gene deployment.
\end{abstract}

Spinach is a popular and nutritious leafy vegetable (Morelock and Correll 2008). The interest in healthier diets and availability of precleaned packaged spinach has caused a dramatic increase in per capita consumption in the United States in the past three decades (National Agricultural Statistics Service, https://www.nass.usda.gov/). Current high-density plant populations for fresh-market spinach production provide conditions conducive for disease development. Also, yearround planting allows for "green bridges" to further facilitate disease development. Downy mildew disease, caused by the obligate pathogen Peronospora effusa (=P. farinosa $\mathrm{f}$. $\mathrm{sp}$. spinaciae, $[P f s])$, is the most economically important disease of spinach (Correll et al. 1994, 2007, 2011) and is frequently found in most spinach production regions. Although "baby" spinach leaves can often be harvested in as little as 21 days after planting, $P f s$ can cause severe damage to this crop owing to the short latent period of the pathogen.

Since the first report of this pathogen infecting spinach in 1824 , only three races had been identified until 1990 (Brandenberger et al. 1991). However, a total of 11 new races of the downy mildew pathogen, races 4 to 14, were identified from 1990 to 2012 (Brandenberger et al. 1991; Feng et al. 2014; Irish et al. 2003, 2007). Although growing resistant cultivars is the most economical way to manage downy mildew, particularly for organic spinach production, cultivars with resistance to known races are typically overcome by new races in a short period of time. Thus, the rapid appearance of new races of this pathogen makes it a challenge to use resistance as a sustainable management tool.

Isolates of $P f s$ that do not fit the reaction pattern of a described race when inoculated onto a standardized set of spinach differentials are periodically recovered and are given a deviating isolate designation. A working group, known as the International Working Group on

${ }^{\dagger}$ Corresponding author: James C. Correll; E-mail: jcorrell@uark.edu

Funding was provided by the California Leafy Greens Research Board.

Accepted for publication 20 October 2017.

C) 2018 The American Phytopathological Society
Peronospora (IWGP), which is hosted by Plantum and based in the Netherlands, meets once or twice a year to determine if a deviating isolate should be nominated and given a race designation. Based on a number of criteria, including how often the deviating isolate is found, in what geographical areas it has occurred, and how it impacts economically important cultivars, the IWGP determines if a deviating isolate is "nominated" to be evaluated by the working group. If nominated, a "ring test" is conducted, whereby inoculum is produced in a single lab and is then distributed to numerous laboratories for testing on the standard set of spinach differentials. If the disease reactions from the various groups are in agreement, and the isolate represents a novel virulence pattern, the isolate is named as a new race. For example, deviating isolate UA4410 was designated as $P f s$ race 14. The announcement typically is done as a coordinated press release in both the United States and the European Union. The overall function of the IWGP is to help facilitate communication among various spinach industry representatives and producers and reduce confusion over which races are present and how spinach cultivars respond to various races. The objectives of the current study were to (i) characterize a number of isolates of the downy mildew pathogen for virulence on a standardized set of spinach differential lines and (ii) evaluate pathogenicity of several of the new races and deviating isolates on a set of near-isogenic lines (NILs) of spinach, the U.S. Department of Agriculture (USDA) spinach germplasm collection, and a set of contemporary spinach hybrid cultivars.

\section{Materials and Methods}

Isolates of $\boldsymbol{P}$. effusa evaluated. A total of 60 isolates of $P f s$ have been tested at the University of Arkansas. These isolates were collected from various spinach production regions; among them, 49 isolates were collected from main spinach production areas in California (CA), Arizona (AZ), and Texas (TX). In addition, single isolates were recovered from Florida (FL), Missouri (MO), New Hampshire (NH), Vermont (VT), Utah (UT), Connecticut (CT), and the Netherlands, and two isolates were collected from Nevada (NV) and New York (NY), respectively (Table 1). The isolates either were directly inoculated on susceptible cultivars and differentials or were stored in a $-80^{\circ} \mathrm{C}$ freezer before inoculating on susceptible cultivars to increase inoculum prior to inoculating differential cultivars. 
Development of spinach NILs. Identification of races of $P f s$ relies on the disease reactions on a standardized set of differentials as determined by the IWGP. The availability of the differential hybrids relies on the supply of various seed companies. The IWGP agreed to

Table 1. Isolates of Peronospora effusa tested at the University of Arkansas between 2013 and $2017^{\mathrm{a}}$

\begin{tabular}{|c|c|c|c|}
\hline Isolate & Host & Geographic origin & Race identification \\
\hline UA4712 & Chevelle & $\mathrm{CA}$ & $P f s 15$ \\
\hline UA5212 & Corvair & $\mathrm{AZ}$ & Pfs 12 \\
\hline UA0313 & Carmel & $\mathrm{CA}$ & Pfs 12 \\
\hline UA1013 & Mandoli & $\mathrm{CA}$ & $P f s 13$ \\
\hline UA1613B & Minorca & FL & UA1012 \\
\hline UA3713 & Dromedary & $\mathrm{CA}$ & UA1312 \\
\hline UA4113 & Plover & $\mathrm{CA}$ & UA1312 \\
\hline UA0514 & Platypus & $\mathrm{AZ}$ & UA1312 \\
\hline UA0614A & SV1846 & $\mathrm{AZ}$ & $P f_{s} 10$ \\
\hline UA1014A & Coati & $\mathrm{AZ}$ & UA1014 \\
\hline UA1414 & unknown & Netherlands & UA1414 \\
\hline UA1914E & Silver Whale & $\mathrm{CA}$ & UA1014 \\
\hline UA3114 & Shelby & $\mathrm{CA}$ & $P f s 14$ \\
\hline UA3414G & Platypus & $\mathrm{CA}$ & UA1014 \\
\hline UA201502A & Gazell & $\mathrm{AZ}$ & UA201502A \\
\hline UA201505 & Platypus & $\mathrm{AZ}$ & $P f s 16$ \\
\hline UA201511A & Caelum & $\mathrm{AZ}$ & UA201511A \\
\hline UA201513 & Rigel & $\mathrm{CA}$ & UA1014 \\
\hline UA201513C & Woodpecker & $\mathrm{AZ}$ & UA201511A \\
\hline UA201516A & Carerra & $\mathrm{CA}$ & UA1014 \\
\hline UA201519B & PV1226 & $\mathrm{CA}$ & Pfs 16 \\
\hline UA201520A & Coati & $\mathrm{CA}$ & Pfs 16 \\
\hline UA201522B & PV1227 & $\mathrm{CA}$ & Pfs 16 \\
\hline UA201523C & Shelby & $\mathrm{CA}$ & Pfs 14 \\
\hline UA201526A & Cello & $\mathrm{CA}$ & UA201502A \\
\hline UA201528A & Kolibri & $\mathrm{CA}$ & $P f_{s} 16$ \\
\hline UA201531E & SV2157 & NV & Pfs 16 \\
\hline UA201533A & SV3580 VC & $\mathrm{NV}$ & UA1012B \\
\hline UA201534A & Carerra & $\mathrm{CA}$ & UA201621A \\
\hline UA201542 & Platypus & $\mathrm{CA}$ & $P f s 16$ \\
\hline UA201550 & Shelby & $\mathrm{CA}$ & UA1012B \\
\hline UA201551 & PV-1202 & $\mathrm{CA}$ & Pfs 16 \\
\hline UA201605 & NAPA & $\mathrm{CA}$ & Pfs 16 \\
\hline UA201607 & Siena & $\mathrm{TX}$ & UA1014 \\
\hline UA201608C & Silver whale & $\mathrm{AZ}$ & UA1014 \\
\hline UA201611A & Sp966 & $\mathrm{AZ}$ & UA1014 \\
\hline UA201611C & Sioux & $\mathrm{AZ}$ & $P f s 14$ \\
\hline UA201614C & Goldeneye & $\mathrm{AZ}$ & UA1014 \\
\hline UA201615F & Bloomsdale & MO & Pfs 3 \\
\hline UA201619 & Platypus & $\mathrm{CA}$ & $P f s 16$ \\
\hline UA201621A & PV1206 & $\mathrm{CA}$ & UA201621A \\
\hline UA201627D & $51-351$ & $\mathrm{CA}$ & UA201621A \\
\hline UA201630 & Stanton & $\mathrm{CO}$ & Pfs 12 \\
\hline UA201641A & 3580 & $\mathrm{AZ}$ & UA201621A \\
\hline UA201646 & Corvair & NY & Pfs 12 \\
\hline UA201648 & Corvair & ME & Pfs 12 \\
\hline UA201650 & Corvair & $\mathrm{CT}$ & Pfs 14 \\
\hline UA201650B & Hydrus & $\mathrm{CA}$ & Pfs14+UA1014 \\
\hline UA201702A & Gallah & $\mathrm{CA}$ & UA201502A \\
\hline UA201703D & DM66-16 & $\mathrm{TX}$ & UA201502A \\
\hline UA201707A & Dozer & $\mathrm{CA}$ & UA201707A \\
\hline UA201707C & $66-16$ & $\mathrm{TX}$ & UA201502A \\
\hline UA201709B & Cursa & $\mathrm{AZ}$ & UA201621A \\
\hline UA201709G & Yuma1 & $\mathrm{AZ}$ & UA201502A \\
\hline UA201711B & Yuma2 975 & $\mathrm{AZ}$ & UA201707A \\
\hline UA201713 & Yuma2 975 & $\mathrm{AZ}$ & UA201707A \\
\hline UA201715 & Avon & UT & $P f_{s} 5$ \\
\hline UA201717 & Sioux & $\mathrm{CA}$ & Pfs 16 \\
\hline UA201718C & Corvair & $\mathrm{NH}$ & Pfs 12 \\
\hline UA201720B & Escalade & NY & UA201720B \\
\hline
\end{tabular}

${ }^{\mathrm{a}}$ The race identification was based on the disease reactions on the standardized set of differentials (Table 2). develop NILs based on the original six hypothesized resistance loci (Correll et al. 2011; Feng et al. 2014). This was done by crossing a given hybrid carrying the desired resistance locus to cultivar Viroflay, a universally susceptible open-pollinated line. After backcrossing four times with the recurrent parent Viroflay, followed by self-pollinating twice, meanwhile selecting for resistance to a given race in each generation, the six NILs were established, each presumably containing one homozygous dominant resistance locus but with the common genetic background of cultivar Viroflay.

Spinach cultivars, hybrids, and advanced breeding lines used for the downy mildew test. A set of spinach differential cultivars and NILs was used for race identification of $P f s$ (Tables 2 and 3). Some contemporary spinach cultivars were used to test for resistance to some new races or novel strains of Pfs (Table 4). In addition, the 360 USDA spinach germplasm accessions were screened for resistance to $P f_{s} 16$ and isolate UA1014.

Spinach seedlings were grown in the greenhouse for inoculation tests. Spinach seed was sown in $25 \times 50$-cm plastic trays filled with potting soil Sunshine LC1 (Sun Gro Horticulture, Canada) with 10 seed rows per flat and 20 seed per row. Plants were grown in the greenhouse $\left(15\right.$ to $\left.25^{\circ} \mathrm{C}\right)$, watered daily, and fertilized weekly with Miracle-Gro All Purpose Plant Food (20-20-20) (2.5 g/L). Twoweek-old seedlings were used for inoculation. The cultivar Viroflay was used to produce more inoculum for inoculation tests as needed.

Inoculation tests and disease rating. A standard procedure was followed for the inoculation and scoring of spinach downy mildew (Irish et al. 2003). Briefly, $P f s$ sporangia were washed off sporulating spinach leaves and then filtered through four layers of cheesecloth. One flat of plants was inoculated with $20 \mathrm{ml}\left(10^{5}\right.$ sporangia/ml $)$ of inoculum by spraying with a Badger basic spray gun (model 250). The inoculated plants were incubated in a dew chamber (100\% relative humidity) at $18^{\circ} \mathrm{C}$ for $24 \mathrm{~h}$ before being moved to the growth chamber at $19^{\circ} \mathrm{C}$ with a $12 \mathrm{~h}$ light $/ 12 \mathrm{~h}$ dark regime for 5 days. Then the inoculated plants were returned to the dew chamber for $24 \mathrm{~h}$ to induce sporulation. The disease was evaluated qualitatively and quantitatively according to the methods of Irish et al. (2003) with minor modifications. Seedlings were scored qualitatively for the presence or absence of sporulation on cotyledons and true leaves as susceptible (+) or resistant $(-)$, respectively. True leaves were scored quantitatively on a scale of 0 to 4 , with $0=$ no sporulation; $1=$ up to $25 \%$ leaf area with sporulation; $2=26$ to $50 \%$ leaf area with sporulation; $3=51$ to $75 \%$ leaf area with sporulation; and $4=$ greater than $75 \%$ leaf area with sporulation. Each isolate was tested a minimum of two times.

\section{Results}

Characterization of two new races ( $P f_{s} 15$ and $P f_{s}$ 16) of the spinach downy mildew pathogen. Race 15 (isolate UA4712) of the spinach downy mildew pathogen was first collected from the cultivar Chevelle in November 2012 in Holtville, CA. This isolate consistently showed a unique disease reaction pattern on the spinach differentials in multiple inoculation tests (Table 2). Isolate UA4712 could infect the differential cultivars Viroflay, Resistoflay, Califlay, Whale, and Caladonia, but not Clermont, Campania, Boeing, Lion, Lazio, and Pigeon. Thus, it could overcome the resistance of $R P F 3$ and $R P F 6$ but not $R P F 1, R P F 2, R P F 4$, or $R P F 5$. The disease reactions of these differential cultivars caused by UA4712 were identical to that of race 4 on the subset of differentials used. However, this isolate could overcome some cultivars with known $P f s 4$ resistance. For example, cultivar Caladonia $(R P F 9 \times R P F 3)$ was resistant to $P f s 4$ but susceptible to isolate UA4712, so the $R P F 9$ locus was not effective against this isolate (Table 2). The IWGP subsequently conducted a ring test with isolate UA4712 and denominated it as race $P f s 15$ in July 2014 (http://ucanr.edu/blogs/blogcore/postdetail.cfm?postnum=15035).

Race 16 (isolate UA201519B) of the spinach downy mildew pathogen was first collected from spinach line PV1226 in May 2015 in Chualar, CA. This isolate also showed a unique disease reaction pattern on the set of spinach differentials. This isolate could infect cultivars Viroflay, Resistoflay, Clermont, Lazio, Pigeon, and Meerkat, but Califlay, Campania, Boeing, Lion, Whale, Tarpy, and Caladonia were resistant (Table 2). This isolate can be differentiated from Pfs 
11 by two cultivars, Pigeon and Meerkat, which were resistant to $P f_{S}$ 11 but susceptible to isolate UA201519B. Pigeon contains the $R P F$ loci $R P F 9$ and $R P F 2$, and Meerkat contains the $R P F$ loci $R P F 10$ and $R P F 2$. Thus, $R P F 1, R P F 3, R P F 6$, and $R P F 7$ were resistant, but $R P F 2, R P F 4, R P F 5, R P F 9$, and $R P F 10$ were susceptible to this isolate (Table 2). Subsequently, the IWGP conducted a ring test with isolate UA201519B and denominated it as race Pfs 16 in February 2016 (http://ucanr.edu/blogs/blogcore/postdetail.cfm?postnum=20476). During 2015 and 2016, a total of 25 isolates collected from CA, AZ, and NV were classified as $P f_{S} 16$ type isolates (Fig. 1).

Characterization of deviating isolates of the downy mildew pathogen. A total of eight isolates of the downy mildew pathogen that had unique disease reaction patterns on the set of spinach differentials were recovered and characterized between January 2013 and May 2017.

Isolate UA1014 was collected from the cultivar Coati in March 2014 in Yuma, AZ. This isolate could infect all spinach differential cultivars (Table 2). However, sporulation could only be found on the cotyledons and not the true leaves of some newer cultivars, such as Meerkat. To ensure that this was not a mixture of multiple isolates, this isolate was inoculated onto the cultivar Lion, which is only susceptible to $P f s 10$ of the 16 named races, and the spores collected on cultivar Lion were inoculated on $P f s 10$ resistant cultivar Pigeon. The disease reactions of the differential cultivars to the purified strain UA1014APLP were identical to that caused by the original isolate UA1014, indicating that this was not a mixture of multiple isolates but a novel strain. During 2014 to 2016, a total of 23 isolates collected from CA, AZ, and TX were identified as having the same disease reactions as the UA1014 type strain (Fig. 1).

Isolate UA1414 was collected from the Netherlands in April 2014. This isolate could infect Viroflay, Resistoflay, Califlay, Clermont, Whale, and Caladonia but not Campania, Boeing, Lion, Lazio, Pigeon, and Meerkat. So it could overcome the resistance of $R P F 3, R P F 4$, $R P F 5$, and $R P F 9$ but not $R P F 1, R P F 2$, and RPF6. The resistance loci $R P F 7$ and $R P F 10$ were not tested with this isolate (Table 2).

Isolate UA201502A was collected from the spinach cultivar Gazelle in January 2015 in Yuma, AZ. It could infect Viroflay, Resistoflay, Califlay, Clermont, Lazio, Whale, Pigeon, Caladonia, and Meerkat. Only Campania, Boeing, Lion, and Tarpy were resistant to this isolate. This isolate could overcome the resistance of $R P F 2$, $R P F 3, R P F 4, R P F 5, R P F 9$, and RPF10 but not RPF1, RPF6, and $R P F 7$ (Table 2). A total of six isolates collected in 2015 and 2017 were the UA201502A type (Table 1).

Isolate UA201511 was collected from the spinach cultivar Caelum in March 2015 in Yuma, AZ. This isolate could infect Viroflay, Resistoflay, Pigeon, and Meerkat but not other differentials. This isolate could overcome the resistances of $R P F 2, R P F 5, R P F 9$, and $R P F 10$ but not RPF1, RPF3, RPF4, and RPF6 (Table 2). The spinach cultivar Tarpy was not tested with this isolate. Another isolate, UA201513C, was also determined to be the UA201511 type (Table 1).

Isolate UA201550 was collected from the spinach cultivar Shelby in December 2015 in Holtville, CA. This isolate could infect cultivars Viroflay, Resistoflay, Clermont, Campania, Boeing, and Tarpy but not Califlay, Lion, Lazio, Whale, Pigeon, Caladonia, and Meerkat. This isolate could overcome the resistance of $R P F 1, R P F 4, R P F 5$, $R P F 6, R P F 7, R P F 9$, and $R P F 10$ but not RPF2 and RPF3 (Table 2). UA201550 caused the same disease reaction on the differentials as the isolate UA1012B. It was not determined if $R P F 9$ and $R P F 10$ were effective against this isolate.

Isolate UA201621 was collected from the spinach line PV1206 in May 2016 in King City, CA. This isolate could infect Viroflay, Resistoflay, Califlay, Whale, Pigeon, Caladonia, and Meerkat but not Clermont, Campania, Boeing, Lion, Lazio, and Tarpy. This isolate could overcome the resistances of $R P F 2, R P F 3, R P F 5, R P F 9$, and

Table 2. Disease responses of spinach differential cultivars to two races ( $P f_{s} 15$ and $P f_{s}$ 16) and eight novel isolates of Peronospora effusa

\begin{tabular}{|c|c|c|c|c|c|c|c|c|c|c|c|c|}
\hline \multirow[b]{2}{*}{ Cultivar } & \multicolumn{2}{|c|}{$\begin{array}{l}\text { Parental } \\
\text { resistance }\end{array}$} & \multirow[b]{2}{*}{ Pfs 15} & \multirow[b]{2}{*}{ Pfs 16} & \multirow[b]{2}{*}{ UA1014 } & \multirow[b]{2}{*}{ UA1414 } & \multirow[b]{2}{*}{ UA201502 } & \multirow[b]{2}{*}{ UA201511 } & \multirow[b]{2}{*}{ UA201550 } & \multirow[b]{2}{*}{ UA201621 } & \multirow[b]{2}{*}{ UA201707A } & \multirow[b]{2}{*}{ UA201720B } \\
\hline & Male & $\overline{\text { Female }}$ & & & & & & & & & & \\
\hline Viroflay & & & $t^{\mathrm{a}}$ & + & + & + & + & + & + & + & + & + \\
\hline Resistoflay & $R P F 5$ & & + & + & + & + & + & + & + & + & + & - \\
\hline Califlay & & $R P F 3$ & + & - & + & + & + & - & - & + & - & - \\
\hline Clermont & $R P F 4$ & RPF5 & ${ }_{-b}^{b}$ & + & + & + & + & - & + & - & + & + \\
\hline Campania & RPF6 & RPF4 & - & - & + & - & - & - & + & - & + & + \\
\hline Boeing & $R P F 1$ & RPF5 & - & - & + & - & - & - & + & - & + & - \\
\hline Lion & $R P F 1$ & $R P F 3$ & - & - & + & - & - & - & - & - & - & - \\
\hline Lazio & $R P F 2$ & RPF4 & - & + & + & - & + & - & - & - & + & + \\
\hline Whale & $R P F 3$ & & + & - & + & + & + & - & - & + & - & - \\
\hline Tarpy & RPF7 & & $\mathrm{nt}^{\mathrm{c}}$ & - & + & nt & - & nt & + & - & + & - \\
\hline Pigeon & $R P F 2$ & RPF9 & - & + & $(+)^{\mathrm{d}}$ & - & + & + & - & + & + & + \\
\hline Caladonia & $R P F 3$ & RPF9 & + & - & $(+)$ & + & + & - & - & + & - & - \\
\hline Meerkat & $R P F 2$ & RPF10 & - & + & $(+)$ & - & + & + & - & + & + & - \\
\hline
\end{tabular}

Table 3. Disease responses of six spinach near-isogenic lines (NILs) to six races ( $P f_{s} 3,5,12,14,15$, and 16) and six novel isolates of Peronospora effusa

\begin{tabular}{|c|c|c|c|c|c|c|c|c|c|c|c|c|c|}
\hline NIL & $\begin{array}{c}\mathbf{R} \\
\text { locus }\end{array}$ & $\begin{array}{c}\text { UA201615F } \\
\quad(P f s 3)\end{array}$ & $\begin{array}{c}\text { UA201715 } \\
(P f s 5)\end{array}$ & $\begin{array}{c}\text { UA201646 } \\
(P f s \text { 12) }\end{array}$ & $\begin{array}{c}\text { UA201650 } \\
(P f s \quad 14)\end{array}$ & $\begin{array}{l}\text { UA4712 } \\
(P f s \text { 15) }\end{array}$ & $\begin{array}{c}\text { UA201519B } \\
\quad(P f s \text { 16) }\end{array}$ & UA1014 & UA201502 & $\begin{array}{c}\text { UA201550 } \\
\text { (UA1012B) }\end{array}$ & UA201621A & UA201707A & UA201720B \\
\hline NIL1 & $R P F 1$ & $-^{\mathrm{a}}$ & - & $t^{\mathrm{b}}$ & + & - & - & + & - & + & - & + & + \\
\hline NIL2 & $R P F 2$ & - & - & + & + & - & + & + & + & - & + & + & + \\
\hline NIL3 & $R P F 3$ & - & - & - & - & + & - & + & + & - & + & - & - \\
\hline NIL4 & RPF4 & - & + & + & + & - & + & + & + & + & - & + & + \\
\hline NIL5 & $R P F 5$ & + & + & + & + & + & + & + & + & + & + & + & - \\
\hline NIL6 & RPF6 & - & - & + & + & - & - & + & - & + & - & + & + \\
\hline
\end{tabular}

$\mathrm{a}_{-}=$A plant without chlorosis or sporulation was rated as resistant.

$\mathrm{b}+=$ A plant showing chlorosis and sporulation on cotyledons, true leaves, or both was classified as susceptible. A spinach line was classified as susceptible if more than $85 \%$ of the plants were susceptible. Typically $>95 \%$ of the plants in a susceptible line show symptoms unless the line is segregating for resistance. 
$R P F 10$ but not RPF1, RPF4, RPF6, and RPF7 (Table 2). This isolate can be differentiated from isolate UA201502A by RPF4 containing cultivars. Four other isolates, UA201534, UA201627D, UA201641A, and UA201709B, caused identical disease reactions on the differentials as isolate UA201621 (Table 1).

Isolate UA201707A was collected from the spinach cultivar Dozer in February 2017 in Holtville, CA. This isolate could infect Viroflay, Resistoflay, Clermont, Campania, Boeing, Lazio, Tarpy, Pigeon, and Meerkat but not Califlay, Lion, Whale, and Caladonia. This isolate could overcome the resistances of $R P F 1, R P F 2, R P F 4, R P F 5$, $R P F 6, R P F 7, R P F 9$, and $R P F 10$, and only $R P F 3$ provided resistance to this isolate. This isolate can be differentiated from $P f s 14$ by Meerkat, which is resistant to Pfs 14 but susceptible to UA201707A (Table 2). Another isolate, UA201711B, was also the UA201707A type (Table 1).

Isolate UA201720B was collected from the spinach cultivar Escalade in May 2017 in Hopewell Junction, NY. This isolate could infect Viroflay, Clermont, Campania, Lazio, and Pigeon but not Resistoflay, Califlay, Boeing, Lion, Whale, Caladonia, and Meerkat. This isolate could overcome the resistances of RPF1, RPF2, RPF4, RPF6, and $R P F 9$, but $R P F 3, R P F 5, R P F 7$, and $R P F 10$ provided resistance to this isolate (Tables 1 and 2).

Resistant loci and use of NILs as race differentials. Several years ago, six $R P F$ resistance loci were hypothesized to be involved in $P f s$ resistance (Correll et al. 2011; Feng et al. 2014). As a result, the IWGP collectively developed a set of NILs. The six NILs were used

Table 4. The disease reactions of 30 contemporary spinach cultivars and breeding lines to race $P f s 16$ and four novel isolates (UA1014, UA201621A, UA201702A, and UA201707A) of Peronospora effusa

\begin{tabular}{|c|c|c|c|c|c|}
\hline Entry & Pfs 16 & UA1014 & UA201621A & UA201702A & UA201707A \\
\hline Sp966 & $-^{\mathrm{a}}$ & $(+)^{\mathrm{b}}$ & - & - & $+^{\mathrm{c}}$ \\
\hline Sp967 & - & $(+)$ & - & - & + \\
\hline SV2146VB & - & $(+)$ & - & - & + \\
\hline Goldeneye & - & $(+)$ & + & + & - \\
\hline PV1206 & - & $(+)$ & + & + & - \\
\hline Antalia & + & $(+)$ & + & + & - \\
\hline Hydrus & - & $-/(+)^{\mathrm{d}}$ & - & - & - \\
\hline Pegasum & + & $-/(+)^{\mathrm{d}}$ & - & + & + \\
\hline $51-348$ & + & $-/(+)^{\mathrm{d}}$ & + & + & + \\
\hline $51-351$ & - & $-/(+)^{\mathrm{d}}$ & + & + & - \\
\hline Caladonia & - & $(+)$ & + & + & - \\
\hline Coati & + & $(+)$ & + & + & + \\
\hline E03D.0579 & - & $(+)$ & + & + & - \\
\hline Mandril & + & $(+)$ & + & + & + \\
\hline Platypus & + & $(+)$ & + & + & + \\
\hline Plover & + & $(+)$ & + & + & + \\
\hline PV-1053 & - & $(+)$ & + & + & - \\
\hline Scorpius & - & $(+)$ & + & + & - \\
\hline Woodpecker & + & $(+)$ & + & + & + \\
\hline SSR-SP-29 & - & + & + & + & - \\
\hline Antalia & + & $(+)$ & + & + & - \\
\hline Cealum & + & $(+)$ & + & + & - \\
\hline Carrera & - & $(+)$ & + & + & - \\
\hline Mandril & + & $(+)$ & + & + & + \\
\hline Shelby & - & $(+)$ & - & - & + \\
\hline Tasman & - & + & + & + & - \\
\hline Virgo & + & $(+)$ & + & + & - \\
\hline Volans & + & $(+)$ & + & + & - \\
\hline PV1202 & + & $(+)$ & - & + & + \\
\hline Wombat & + & $(+)$ & + & + & - \\
\hline
\end{tabular}

a $-=$ A plant without chlorosis or sporulation was rated as resistant.

$\mathrm{b}(+)=$ Symptoms and sporulation were observed on cotyledons only and not on true leaves.

${ }^{c}+=$ A plant showing chlorosis and sporulation on cotyledons, true leaves, or both was classified as susceptible. A spinach line was classified as susceptible if more than $85 \%$ of the plants were susceptible. Typically $>95 \%$ of the plants in a susceptible line show symptoms unless the line is segregating for resistance.

${ }^{\mathrm{d}}$ For the lines indicated, the results varied for individual tests. to evaluate disease reactions from six races $\left(P f_{s} 3,5,12,14,15\right.$, and 16) and six novel strains (UA1014, UA201502, UA201550, UA201621A, UA201707A, and UA201720B) of $P f s$ (Table 3). Both NIL1 and NIL6 were resistant to three races ( $P f_{s} 3, P f s$ 15, and $P f s$ 16) and two novel strains (UA201502A and UA201621A) but susceptible to races $P f s 12$ and $P f s 14$ and to strains UA1014, UA1012B, UA201707A, and UA201720B. NIL3 was also resistant to Pfs 3, $P f s$ 16, and UA201720B and susceptible to UA1014, but the disease reactions of the other eight strains tested were opposite to that of NIL1 and NIL6. Both NIL2 and NIL4 had resistance to Pfs 3 and Pfs 15, but they can differentiate the two strains UA1012B and UA201621A. NIL5 was resistant to US201720B but susceptible to the other 10 strains tested. Based on the disease reactions of NILs to the nine strains tested, only $R P F 5$ was susceptible to $P f s$, and only $R P F 3$ was resistant to $P f s$ 12, $P f_{s}$ 14, and US201707A. All six loci ( $R P F 1$ to $R P F 6$ ) were susceptible to the novel strain UA1014 (Table 3).

Other resistance loci were also found in spinach cultivars and/or hybrids. Cultivar Tarpy has resistance to $P f s 1$ to 7 but is susceptible to $P f s$ to 10 (Irish et al. 2007). This disease reaction pattern cannot be any combination of RPF1 to RPF6; thus, Tarpy has a unique resistance locus, $R P F 7$. The NIL7 containing $R P F 7$ is under development. The hybrid cultivar Pigeon containing $R P F 2$ and a new resistance locus provided resistance to $P f s 11$ to 13 . The resistance locus in Pigeon that provided resistance to $P f s 11$ to 13 was designated RPF9. Similarly, hybrid Meerkat containing RPF2 and a new resistance locus provides resistance to $P f s 11$ to 14 . Thus, the resistance locus in Meerkat that provided resistance to $P f s 11$ to 14 was designated $R P F 10$. New cultivars containing a few unidentified resistance loci originating from wild germplasm have been evaluated but need further study.

Screening USDA spinach germplasm and new cultivars for resistance to novel strains. Because the six described resistance loci were susceptible to UA1014, 360 accessions of USDA spinach germplasm (https://www.ars-grin.gov/npgs/index.html) were screened for resistance to this isolate. However, none of these accessions was resistant to UA1014. The same set of germplasm was then tested against $P f s$ 16. Similarly, no resistance was found among the 360 accessions to the race $P f s 16$.

Subsequently, strains UA1014 and UA201519B ( $P f s$ 16) and three other novel strains (UA201621A, UA201702A, and UA201707A) were evaluated on a number of newly released contemporary spinach cultivars and advanced breeding lines. Among these cultivars, Tasman and line SSR-SP-29 showed infection on both the cotyledons and true leaves to UA1014. Sporulation was only found on the cotyledons and not the true leaves of the other cultivars tested (Table 4). However, when inoculated with UA1014, some conflicting results were recorded in that sporulation was found on the cotyledons of Hydrus, Pegasum, 51-348, and 51-351 in several but not all tests. With the other deviating isolates, 15 of the 30 new cultivars tested had resistance to $P f s$ 16. Seven and five of the 30 lines tested were resistant to isolates UA201621A and UA201702A, respectively. The cultivars Pegasum and PV1202 were resistant to UA201621A but susceptible to UA201702A. There were 17 lines resistant to UA201707A.

Survey of spinach downy mildew pathogen from 2013 to 2017. In the past four and a half years, 137 opportunistic samples of isolates of the spinach downy mildew pathogen were characterized for pathogenicity on a set of spinach differentials. Among the 137 samples examined over the 4-year period, 45 belonged to previously characterized races $P f_{s} 3,10,11,12,13$, and 14; 28 isolates belonged to the two new races $P f s 15$ and 16. A total of 64 isolates represented eight isolates deviating from previously characterized races.

Among the 26 samples collected in 2013, $P f s$ races 10 to 15 were identified, whereas races 13 and 12 were the two most predominant. In addition, one UA1210 type, one UA1012 type, and three UA1312 type isolates also were found in 2013. In 2014, one isolate each of races 11 and 13 along with two isolates each of races 10 and 14 were identified. A total of six isolates of the UA1312 type isolate and four of the UA1014 type isolate were identified in 2014. Four isolates were found to be mixtures of $P f s$ strains. In 2015,11 isolates were 
identified as $P f s$ 16, making it the predominant type identified. Seven isolates of the UA1312 type, six Pfs race 14 type isolates, and three UA1014 type isolates were also identified in 2015. A total of 14 and 16 isolates of $P f s 16$ and UA1014 type, respectively, were identified in 2016, and these were the predominant types identified. In addition, three isolates each of $P f s 12$ and 14 along with one each of $P f s 11$ and 15 were identified in 2016. In addition to one isolate each of $P f s 5$, $P f s$ 12, and $P f s$ 16, four isolates of UA201502A type, three isolates of UA201707A type, and one UA201720B isolate were identified in 2017. The major races and novel strains found during 2013 to 2016 are shown in Figure 1.

\section{Discussion}

Two new races of $P f s$ were identified in the course of this study: race 15 (isolate UA4712) and race 16 (isolate UA201519B). Both isolates were confirmed to have unique virulence patterns on the international set of differentials, further verified in a ring test with multiple laboratories and sanctioned by the IWGP. In addition, eight novel deviating strains were identified during the course of the study.

In the last 4 years, 137 isolates of the spinach downy mildew pathogen have been tested at the University of Arkansas, Fayetteville, AR, and University of California Cooperative Extension, Salinas, CA. The previously described $P f s$ races, 3, 5, 10, 11, 12, 13, and 14 were found in the survey. For example, one $P f s 3$ type isolate was collected on the older spinach cultivar Bloomsdale grown in MO, one $P f s 5$ type isolate was collected on the older cultivar Avon grown in UT, and three $P f s 12$ type and one $P f s 14$ type isolates were collected on the cultivar Corvair grown in the NY, ME, and CT (Table 1). The survey also identified two new races and eight novel strains of the spinach downy mildew pathogen during this period (Table 2). The data highlighted the continued emergence of new virulence combinations in the pathogen population.

Observations of oospores in leaf tissue (Feng et al. 2014) and analysis of population diversity (Lyon et al. 2016) indicated that sexual recombination contributes to genetic variation. Sexual recombination of the pathogen, the current production system of high-density spinach plantings that creates a favorable environment for disease development, and the use of resistant cultivars with new combinations of resistance genes likely put a strong selection pressure on the pathogen, which may contribute to the continued emergence of new races of $P f s$.
The disease reactions of the NILs containing individual $R P F$ loci clearly revealed the effectiveness of the various $R P F \mathrm{~s}$ to the spectrum of races of $P f s$ present in commercial production fields. The NILs are homozygous dominant at the target resistance locus, which has been introgressed into a common genetic background (Viroflay) (Irish et al. 2008). The NILs are open-pollinated lines and can be more easily maintained than hybrid cultivars that have been used as differentials. Thus, the NILs are useful for spinach downy mildew race identification and molecular marker development (Irish et al. 2008). Several described and proposed resistance loci exist in some cultivars, and the development of new NILs containing these other resistance loci would be valuable (Brugmans et al. 2015a, b; Dijkstra 2015a, b; Dijkstra and Raedts 2017; Feitsma and Kock 2016).

The isolate UA1014 had a unique phenotype relative to other isolates of $P f s$ examined. This isolate could overcome the resistance of $R P F 1$ to RPF7 and may cause damage to spinach production on cultivars containing any combination of these loci. Interestingly, some newer cultivars had a somewhat novel reaction to this isolate. For some cultivars, the disease was observed on cotyledons but not true leaves when lines were evaluated. This phenomenon has previously been observed in spinach and has been hypothesized to be caused by minor genes distinct from the known major $(R P F)$ genes (Brandenberger et al. 1991). In the current tests, there were even some inconsistencies in the reactions on cotyledons (Table 4), indicating that the quantitative level of infection may be owing to variables such as temperature, nutritional status of the plants, and so on.

Although the standardized test for identifying disease reactions to $P f s$ in spinach has been based solely on cotyledon reactions (http:// www.worldseed.org/our-work/plant-health/differential-hosts/), it has become apparent that some genotypes have intermediate, or quantitatively different, reactions to various isolates, leading to the somewhat difficult to define term of "intermediate" resistance often claimed by seed companies. Reducing infection or sporulation on cotyledons, and differential reactions between cotyledons and true leaves may be the result of the presence of minor genes, or perhaps major genes being present in a heterozygous condition. In addition, this quantitative type of resistance observed in spinach has been shown to be race specific (Irish et al. 2003). Similar phenomena were found in host-pathogen systems such as Cucumis melo (muskmelon) and Sphaerotheca fuliginea (Cohen and Eyal 1995), Arabidopsis thaliana and Hyaloperonospora arabidopsidis (Krasileva et al.

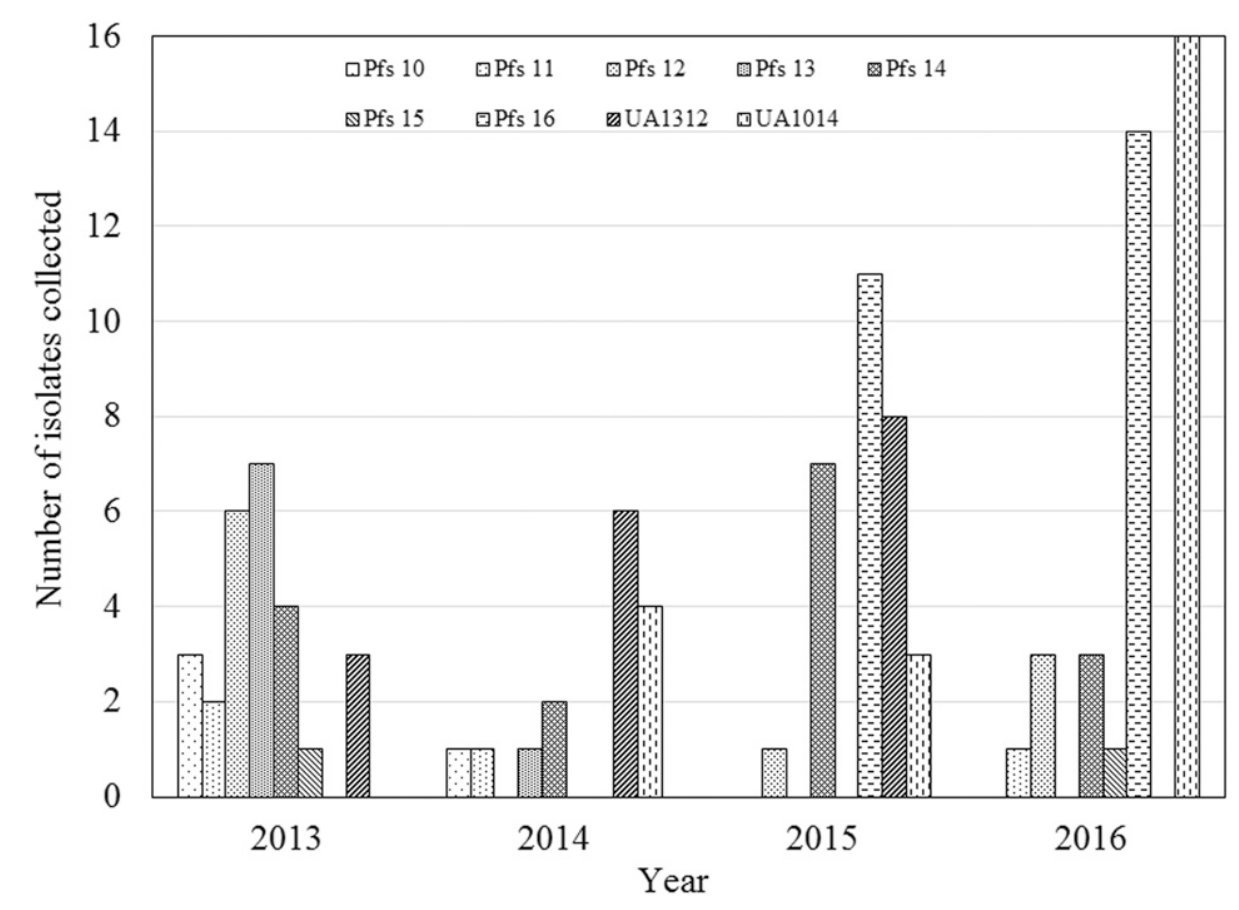

Fig. 1. Frequencies of seven races and two novel isolates of the spinach downy mildew pathogen based on 113 samples of Peronospora effusa (Pfs) collected from 2013 to 2016. 
2011; McDowell et al. 2005), and Brassica oleracea (broccoli) and Peronospora parasitica (Wang et al. 2000). A single dominant gene was found for cotyledon resistance in broccoli line USVL089, which also provided resistance in the true leaves (Farnham et al. 2002). The true leaf resistance in broccoli to downy mildew was controlled by two complementary dominant genes in broccoli line USVL012 (Wang et al. 2001). The cotyledons of many of the newer spinach cultivars were susceptible but true leaves were resistant to UA1014, suggesting either that the resistance is expressed differentially by age or tissue or that it is controlled by different genes. How such cultivars would perform with high pathogen pressure under conducive field conditions is not known.

No resistance to UA1014 or $P f s 16$ was found among the 360 USDA spinach germplasm entries evaluated. However, the USDA spinach germplasm and other international collections are somewhat limited with regard to resistance to $P f s$ (Morelock and Correll 2008; Van Treuren et al. 2012). More recent spinach germplasm collections made by a consortium of Dutch companies have provided some new resistance sources to the spinach downy mildew pathogen (Kik 2013). However, it is apparent, owing to the virulence diversity of this important pathogen, that additional sources of resistance are needed to continue to manage downy mildew on spinach.

\section{Acknowledgments}

We thank the following for their assistance: Rikki Minkler, Jaclyn B. Gordon, and Carlos Rodriguez.

\section{Literature Cited}

Brandenberger, L. P., Correll, J. C., and Morelock, T. E. 1991. Identification of and cultivar reactions to a new race (race-4) of Peronospora farinosa $\mathrm{f}$. $\mathrm{sp}$. spinaciae on spinach in the United States. Plant Dis. 75:630-634.

Brugmans, B. W., Fernandez, E. L., and Weber, I. 2015a. U.S. patent no. WO 2015/054339 A9.

Brugmans, B. W., Meeuwsen, J., and Nooyen, C. 2015b. U.S. patent no. US 2015/ 0240256A1.

Cohen, Y., and Eyal, H. 1995. Differential expression of resistance to powdery mildew incited by race 1 or 2 of Sphaerotheca fuliginea in Cucumis melo genotypes at various stages of plant development. Phytoparasitica 23:223-230.

Correll, J. C., Bluhm, B. H., Feng, C., Lamour, K., du Toit, L. J., and Koike, S. T. 2011. Spinach: Better management of downy mildew and white rust through genomics. Eur. J. Plant Pathol. 129:193-205.

Correll, J. C., Feng, C., Irish, B. M., Koike, S. T., Morelock, T. E., Bentley, T. C., and Tomlinson, A. N. 2007. Spinach downy mildew: Overview of races and the development of molecular markers linked to major resistance genes. Pages
135-142 in: Advances in Downy Mildew Research, Vol. 3. A. S.-P. Lebeda and P. T. N. Spencer-Phillips, eds. Palacký University, Olomouc, Czech Republic.

Correll, J. C., Morelock, T. E., Black, M. C., Koike, S. T., Brandenberger, L. P., and Dainello, F. J. 1994. Economically important diseases of spinach. Plant Dis. 78:653-660.

Dijkstra, J. A. 2015a. Netherlands patent no. WO 2015/036378 A1.

Dijkstra, J. A. 2015b. U.S. patent no. US 2015/0082483 A1.

Dijkstra, J. A., and Raedts, R. 2017. U.S. patent no. US 2015/0027127 A1.

Farnham, M. W., Wang, M., and Thomas, C. E. 2002. A single dominant gene for downy mildew resistance in broccoli. Euphytica 128:405-407.

Feitsma, J. G. J., and Kock, V. L. A. 2016. U.S. patent no. US9402363 B1.

Feng, C., Correll, J. C., Kammeijer, K. E., and Koike, S. T. 2014. Identification of new races and deviating strains of the spinach downy mildew pathogen Peronospora farinosa f. sp spinaciae. Plant Dis. 98:145-152.

Irish, B. M., Correll, J. C., Feng, C., Bentley, T., and de los Reyes, B. G. 2008. Characterization of a resistance locus $(P f s-1)$ to the spinach downy mildew pathogen (Peronospora farinosa f. sp. spinaciae) and development of a molecular marker linked to $P f s-1$. Phytopathology 98:894-900.

Irish, B. M., Correll, J. C., Koike, S. T., and Morelock, T. E. 2007. Three new races of the spinach downy mildew pathogen identified by a modified set of spinach differentials. Plant Dis. 91:1392-1396.

Irish, B. M., Correll, J. C., Koike, S. T., Schafer, J., and Morelock, T. E. 2003. Identification and cultivar reaction to three new races of the spinach downy mildew pathogen from the United States and Europe. Plant Dis. 87:567-572.

Kik, C. 2013. Two collecting expeditions to the centres of biodiversity of spinach. Page 40 in: International Spinach Conference, Guangzhou, China.

Krasileva, K. V., Zheng, C., Leonelli, L., Goritschnig, S., Dahlbeck, D., and Staskawicz, B. J. 2011. Global analysis of Arabidopsis/downy mildew interactions reveals prevalence of incomplete resistance and rapid evolution of pathogen recognition. PLoS One 6:e28765.

Lyon, R., Correll, J., Feng, C., Bluhm, B., Shrestha, S., Shi, A., and Lamour, K. 2016. Population structure of Peronospora effusa in the southwestern United States. PLoS One 11:e0148385.

McDowell, J. M., Williams, S. G., Funderburg, N. T., Eulgem, T., and Dangl, J. L. 2005. Genetic analysis of developmentally regulated resistance to downy mildew (Hyaloperonospora parasitica) in Arabidopsis thaliana. Mol. PlantMicrobe Interact. 18:1226-1234.

Morelock, T. E., and Correll, J. C. 2008. Spinach. Pages 189-218 in: Vegetables I Asteraceae, Brassicaceae, Chenopodicaceae, and Cucurbitaceae. J. Prohens and F. Neuz, eds. Springer, New York, NY.

Van Treuren, R., Coquin, P., and Lohwasser, U. 2012. Genetic resources collections of leafy vegetables (lettuce, spinach, chicory, artichoke, asparagus, lamb's lettuce, rhubarb and rocket salad): Compositions and gaps. Genet. Resour. Crop Evol. 59:981-997.

Wang, M., Farnham, M. W., and Thomas, C. E. 2000. Phenotypic variation for downy mildew resistance among inbred broccoli. HortScience 35:925-929.

Wang, M., Farnham, M. W., and Thomas, C. E. 2001. Inheritance of true leaf stage downy mildew resistance in broccoli. J. Am. Soc. Hortic. Sci. 126:727-729. 